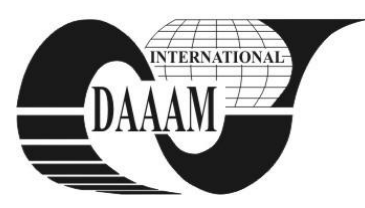

Annals of DAAAM for 2012 \& Proceedings of the 23rd International DAAAM Symposium, Volume 23, No.1, ISSN 2304-1382 ISBN 978-3-901509-91-9, CDROM version, Ed. B. Katalinic, Published by DAAAM International, Vienna, Austria, EU, 2012 Make Harmony between Technology and Nature, and Your Mind will Fly Free as a Bird Annals \& Proceedings of DAAAM International 2012

\title{
THE IMPROVED SYSTEM FOR AUTOMATION AND OPTIMIZATION OF SOLID MATERIAL GRINDING BY MEANS OF BALL MILLS
}

\author{
FEDORYSHYN, R[oman]; NYKOLYN, H[ryhoriy]; ZAGRAJ, V[olodymyr] \& PISTUN, Y[evhen]
}

\begin{abstract}
This work deals with the system for automated control and optimization of the technological process of solid material grinding by means of ball mills, which are being applied at heat power stations for grinding the coal, at cement plants for grinding the clinker and at ceramic plants for grinding the clay. The developed system provides continuous monitoring of the grinding, ventilating and drying productivities and it optimizes the mill performance in order to reach the maximum possible grinding productivity. Application of the system provides safe operation of the mill in automatic mode, reduction of specific energy consumption for grinding a unit weight of the solid material (by 5 to $30 \%$ depending on the type of the mill) as well asconsiderable increase of the grinding productivity of the mill. Keywords: ball mill, grinding, automation, optimization, efficiency
\end{abstract}

\section{INTRODUCTION}

The technological processes of solid material grinding by means of ball mills are of great importance for many branches of industry. They are of particular importance for efficient operation of heat power stations consuming coal as the energy carrier, for cement plants where clinker is grinded, for ceramic plants where clay is grinded and for other plants. A specific feature in running a ball mill is that the grinding mills are big power consumers, since grinding process is power-intensive. The electric power consumption for solid material grinding amounts up to about $20 \%$ of the total power consumption for own needs of the plant or about $2 \%$ of the total amount of power produced by the heat power station [1].

A ball mill consists of a cylindrical steel drum (with the size of 2 to $5 \mathrm{~m}$ in diameter and 3 to $15 \mathrm{~m}$ in length) and steal balls (up to $25 \mathrm{~cm}$ in diameter) inside of it (see Fig. 1). The drum is being rotated by means of an electric drive (with power consumption of up to $1 \mathrm{MW}$ ). The raw material is fed into the mill at the inlet side of the drum by means of a feeder and the grinded material is taken away at the outlet side of the drum by means of the ventilation system. This is how grinding in a ball mill takes place [2].

The relation between grinding productivity and loading of a ball mill by the material is proportional. The more material is fed into the mill the higher grinding productivity. But at some point there is too much material in the mill and the material is not grinded any more, the grinding productivity decreases abruptly down to zero and the mill blockage takes place (see Fig. 2). Depending on the properties of the solid material and on characteristics of the dust system, the mill blockage may take place at various loadings of the mill. This is an emergency situation and it should be avoided.

\section{PECULIARITIES OF BALL MILL AUTOMATION}

The process of solid material grinding in ball mills has been automated poorly, because there were no methods to measure the main parameters of the grinding process, such as amount of the material in the mill, grinding productivity and especially there were no methods to determine the pre-failure condition in which the mill is so much overloaded with the material being ground that it leads to abrupt decrease in its grinding productivity and to blockage. In order to prevent the failure of a mill the operators deliberately decrease the grinding output by feeding less material to the mill, which makes the grinding process more power-intensive and less efficient [1]. There were no reliable methods to find the optimal loading of a mill in order to reach the maximum possible grinding productivity.

Many investigators, however, with a purpose of ball mill automation, have carried out experimental studies and established relations between the main technological parameters of the grinding process and a number of indirect indexes [3], [4]. Based on these studies, various schemes for automation of ball mills have been proposed: to regulate the outlet temperature of the air mixture, to regulate the differential pressure across the mill drum and to regulate the acoustic signal of the mill. But all those systems could not ensure the maximum possible grinding productivity and they did not prevent a possible blockage of the mill.

The maximum possible grinding productivity depends on the properties of the solid material (grain composition, grinding ability index, rock concentration,

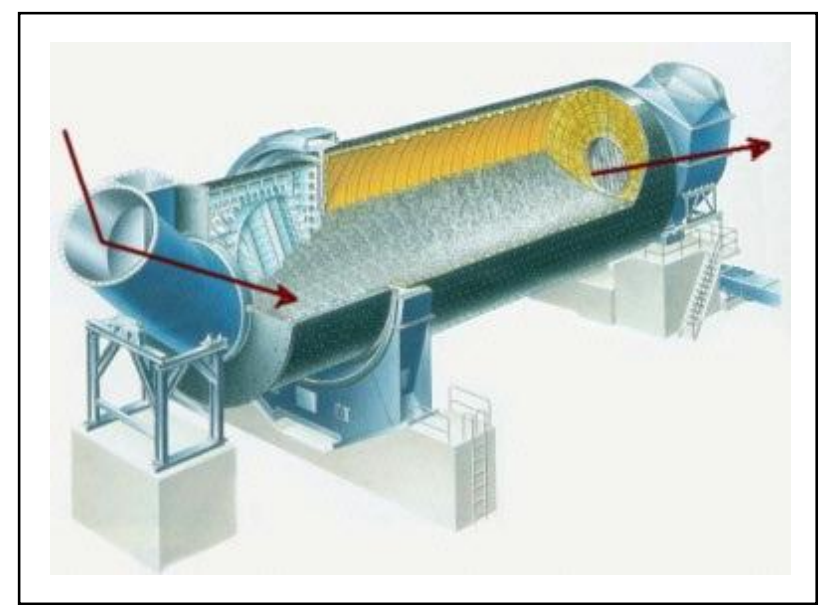

Fig. 1. Ball mill cut-away (picture from www.mine-engineer.com) 


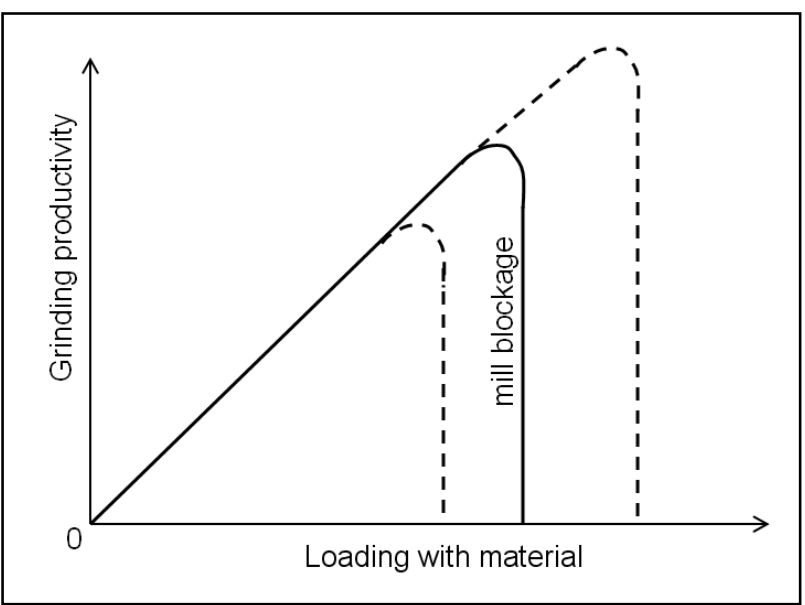

Fig. 2. Grinding productivity of a ball mill versus loading of the mill with the solid material

moisture content etc.), on the characteristics of the dust system (drying ability, ventilating ability and grinding ability), on the amount of material fed into the mill and on the feeding system and its regime [5].

The main companies dealing with automation of grinding processes are Siemens, Schenk, Brüel \& Kjær and other. A great deal of attention is paid by these companies to automation of roller mills and less attention is paid to automation of ball mills. Another specific feature is that the existing ball mill automation systems do not provide optimization of ball mill loading in order to reach maximum grinding productivity.

The experience of using the systems developed earlier has put forward the task to improve them and to create new algorithms for calculation of actual values of the main technological parameters of the grinding process, including a new method to measure the amount of material in the mill. Another task was to develop new algorithms in order to optimize mill performance both under standard conditions and under constraints on drying ability and ventilating ability of the dust system [6]. It was also necessary to take additional measures to provide safe operation of the mill and to try out failure situations. In order to fulfill all the above tasks a ball mill automation and optimization system was developed (see Fig. 3).

\section{DESCRIPTION OF THE DEVELOPED BALL MILL AUTOMATION SYSTEM}

The structural diagram of the developed ball mill automation and optimization system is shown on Fig. 4. A piezoceramic accelerometer is mounted on the front bearing of the mill and it measures the vibration acceleration of the mill bearing. This signal correlates directly with the mill loading with the material to be ground. Another piezoceramic accelerometer is mounted on the back bearing of the mill and its signal correlates with the quality of the grinding process (fineness of grinding). The interrelation between these parameters is monitored by the controlleroptimizer. A temperature transducer is applied to measure the temperature of the air mixture at the mill outlet. A differential pressure transducer is applied to measure the differential pressure across the drum of the mill.
The output signals of all the transducers are $4 \div 20 \mathrm{~mA}$ and they are attached to the appropriate analogue inputs of the controller-optimizer. A control key on the controlleroptimizer switches the system to the manual control mode "Distance" or automatic control mode "Automatic". The material is fed into the mill by means of a raw material feeder controlled directly by the controller-optimizer. The controlling action of the controller-optimizer is performed by regulating the rotation frequency of the feeder drive. The system is equipped with a controlling relay which is switched on by the controller-optimizer when the air mixture temperature exceeds the maximum limiting value in order to stop material feeding and to ensure dust system safety.

The values of air mixture temperature at the mill outlet, differential pressure across the mill drum and relative values of mill loading by the material are displayed at the front panel of the controller-optimizer. Also the limits of air mixture temperature and the information on the current condition of the controlleroptimizer are displayed. The minimum and maximum values of air mixture temperature and of differential pressure across the mill drum (Tmin, Tmax, $\Delta \mathrm{Pmin}$, $\Delta$ Pmax) are adjusted for each mill type and for each type of dust preparation system individually.

Depending on the properties of material and characteristics of the dust system the maximum possible grinding productivity of the mill is reached at the level of 80 to 95 per cent of the maximum possible loading of the mill with the material being ground [7].

The maximum grinding productivity in operating conditions is sometimes constrained by drying ability and ventilating ability of the dust system. The deficiency of ventilating ability may take place due to large moisture content in the material being ground relative to the nominal value and deficiency of drying ability may take place due to decrease of temperature of drying agent.

Low drying ability of the dust system is usually characterized by air mixture temperature decrease at the mill outlet below the minimum limit. Deficiency of ventilating ability may be caused by blockages of the inlet and outlet throats of the ball mill (the differential pressure across the mill drum exceeds the maximum limiting value).

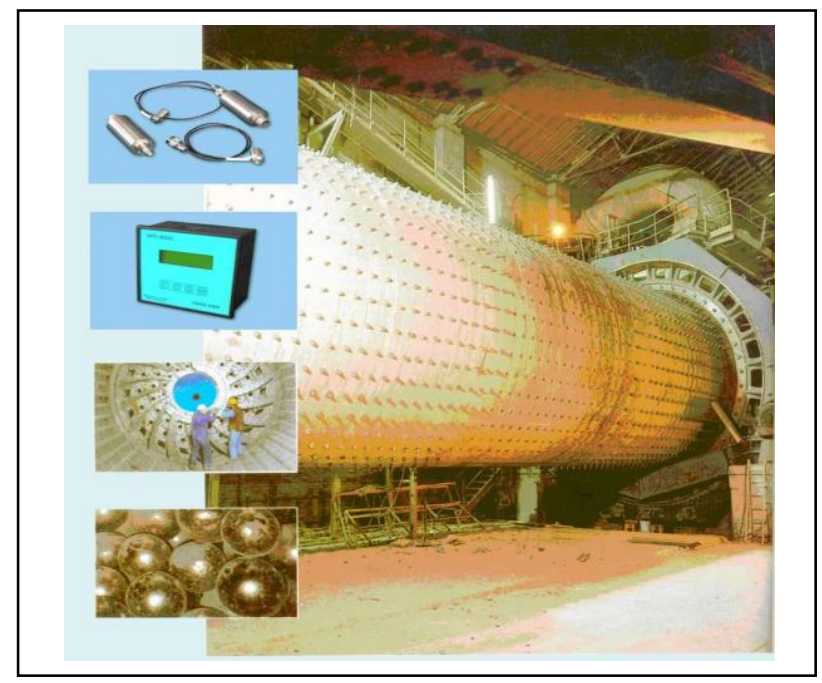

Fig. 3. Some elements of the developed ball mill automation and optimization system 


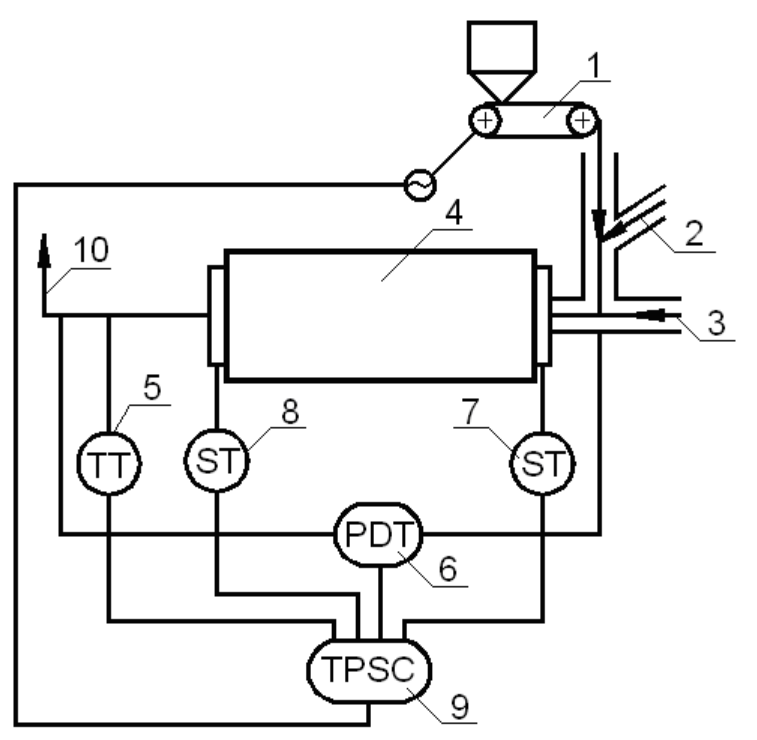

Fig. 4.Structural diagram of the ball mill automation and optimization system: 1 - raw material feeder (RMF); 2 - from separator; 3 - drying agent; 4 - ball mill; 5 - temperature transducer; 6 - differential pressure transducer; 7,8-piezoceramic accelerometers; 9 - controller-optimizer; 10 - to separator

During operation of a ball mill it is especially important to avoid the exceeding of the maximum limiting temperature of the air mixture, which can result in an explosion of the dust system. Therefore the developed ball mill automation system provides a mechanism to prevent overheating of the air mixture. A sound alarm is provided to give a signal of a pre-failure situation with a possibility to interrupt the supply of a heating agent. In order to safeguard the dust system the precautionary measures are taken by the automation system to avoid the temperature going out of the specified range and to avoid the exceeding of the maximum limiting value of the differential pressure across the mill drum.

According to a specially developed algorithm the controller of the automation system adjusts automatically to the existing dust system, grinding ability of the mill and to the qualitative properties of the material being ground. As these parameters vary the controller adjusts automatically to regulate the material feeding so that the grinding productivity is always maximal. When there are constraints in the dust system on drying ability, ventilating ability or maximum temperature of the air mixture at the mill outlet the material is fed in such a way that the temperature of the air mixture at the mill outlet is maintained within the specified limits and the differential pressure across the mill drum does not exceed the maximum limiting value.

The task of the main operation mode of the controller-optimizer is to ensure such a feeding of raw material into the mill at which the maximum possible grinding productivity is reached and the ball mill operates on the peak of the curve of grinding productivity (see Fig. 2). The controller-optimizer switches to other modes when there are constraints on the mill's drying ability or ventilating ability, as well as when the pre-failure situations occur. When the system goes outside of the limiting conditions, the controller-optimizer switches to the dynamic optimization mode in search for an optimal loading of the mill by the material.

When there are no constraints on the drying ability and ventilating ability of the mill and when there is no pre-failure situation the controller-optimizer operation mode is determined by the relative degree of mill loading. So when the relative degree of mill loading is less than $40 \%$, the material is fed into the mill continuously at the maximum possible productivity of the feeder. In other cases the material is fed into the mill according to a special algorithm until the maximum value of loading degree is reached. As soon as the optimal value of the mill loading is reached, when the dust system operates at the maximum possible productivity, the controller-optimizer maintains this value as long as the technological process conditions do not change.

The productivity of raw material feeder should be 1.5 - 2 times higher than the mill's grinding productivity. This is the main condition to ensure normal running of the technological process of material grinding in the mill. When the feeder productivity is insufficient, the controller-optimizer operates in a non-standard mode which is characterized by a lower degree of mill loading. This, in turn, results in an inefficient operation of the dust system.

Insufficient drying ability and ventilating ability of the mill are also limiting factors for reaching the maximum possible grinding productivity of the mill. When such constrains occur optimization of mill operation is possible only within the specified constraints.

\section{THE MAIN FEATURES OF THE DEVELOPED BALL MILL AUTOMATION AND OPTIMIZATION SYSTEM}

The developed ball mill automation and optimization system provides accomplishment of the following tasks:

- Measurement and calculation of three main technological parameters: loading degree of the ball mill with the material being ground, air mixture temperature at the mill outlet and the differential pressure across the mill drum.

- Optimization of the grinding process including continuous search and maintaining of the ball mill loading degree by regulating the feeding of solid material into the mill in order to ensure the maximum possible grinding productivity of the mill.

- Continuous monitoring of drying ability and ventilating ability of the dust system, and in case of decrease of these parameters down to critical values optimization of mill operation within allowable constraints.

- Dynamic optimization of the grinding process when the system is switched from the modes with specified constraints or from unloaded condition to optimal loading mode. 
- Visualization of controller operation modes, current values of the mill loading degree, the air mixture temperature at the mill outlet and the differential pressure across the mill drum, as well as minimum and maximum limits of the air mixture temperature and the differential pressure across the mill drum.

- Signalization of work and stops of raw material feeder, occurrence of constraints on dust system drying ability and ventilating ability, exceeding of the maximum limiting temperature value of the air mixture, existence of pre-failure situations.

- Prevention of mill blockage by the material being ground.

- Guarantee of safe operation of the dust system in automatic mode.

One more feature provided by the developed ball mill automation and optimization system is protection of the electric drive of the mill. If the drive is overloaded the system will switch it off in order to prevent the breakdown of the drive.

The ball mill automation and optimization system was developed by scientists of Lviv Polytechnic National University together with experts from "Techprylad" Research and Design Production Company (Lviv, Ukraine). We are working in the field of automation of industrial processes and automation of ball mills in particular for more than 20 years.

\section{IMPLEMENTATION OF THE DEVELOPED BALL MILL AUTOMATION AND OPTIMIZATION SYSTEM}

The developed automation and optimization system was installed at a number of ball mills at heat power stations for grinding the coal, at cement plants for grinding the clinker and at ceramic plants for grinding the clay.

One of the systems was installed at a heat power station where three ball mills were used to grind the coal for a $300 \mathrm{MW}$ power generating unit. Application of the developed ball mill automation and optimization system provided raising of grinding productivity of the mills in such a way that the productivity of two mills was enough for preparation of the fuel for the power generating unit and the third mill was turned off. This is how energy saving by $30 \%$ at coal grinding was reached.

Another system was installed at a heat power station for automation of two ball mills for coal grinding. The total grinding productivity of the mills was 20 tons per hour. After installation of the system the total grinding productivity of the two mills increased up to 23 tons per hour and pauses in operation of each mill were provided which resulted in significant saving of electric energy.

Thanks to the developed ball mill automation and optimization system the technological and financial benefits are provided to the companies where ball mills are applied for solid material grinding. The main technological benefits are in reduction of the electric power consumption, increase in grinding productivity and improvement of reliability at ball mill operation. The financial benefits are in spending less money for grinding a unit weight of solid material due to the increased grinding productivity and the reduced power consumption.

\section{CONCLUSIONS}

A new ball mill automation and optimization system is developed. Application of the system provides improvement of the main paramenters of the technological process of solid material grinding by means of ball mills, which are being applied at heat power stations for grinding the coal, at cement plants for grinding the clinker and at ceramic plants for grinding the clay.

Implementation of the system ensures a considerable increase in grinding productivity of a ball mill irrespective of the quality characteristics of the material being ground and irrespective of the condition of the dust system. It also consumes less power per unit weight of the material being ground.

\section{ACKNOWLEDGEMENTS}

The research has been supported by the Business Partnership Grant from U.S. Civilian Research and Development Foundation (CRDF Global) and the State Agency of Ukraine for Science, Innovations and Information.

\section{REFERENCES}

[1] Levit, G. (1991). Production of Dust at Thermoelectric Power Stations, Energoatomizdat Publishing House, ISBN 5-283-001512, Moscow (Russia)

[2] Perov, V.; Andreev, E. \& Bilenko, L. (1990). Grinding, Milling and Screening of Mineral Products, Nedra Publishing House, ISBN 5-247-00984-3, Moscow (Russia)

[3] Touil, D.; Belaadi, S. \& Frances, C. (2006). Energy efficiency of cement finish grinding in a dry batch ball mill, Cement and Concrete Research, volume 41, issue 3, pp. 416-421 Elsevier Ltd., (France)

[4] Shuvalov, S.; Mikheev, P; Verenin, A. \& Astashov, N. (2009). Mathematical model of ball pulverizer mill for analysis of pulverized coal separator operation, Proceedings of IGEU, volume 3, Ivanovo (Russia)

[5] Formusatin, V. (2010). Improving Dust-System's Performance with Ball-Tube Mills, Available from: http://dustsystem.narod.ru Accessed: 2010-09-15

[6] Tsakalakis, L. \& Stamboltzis G. (2004). Modeling the Specific Grinding Energy and Ball Mill Scaleup, Proceedings of 11 IFAC Symposium, September 08-10, 2004, ISBN 0-08-0441793, Sauter, D. \& Theilliol D. (Ed.), pp. 53-58, Elsevier Ltd., Nancy (France)

[7] Fedoryshyn, R.; Zagraj, V. \& Pistun, Y. (2011). Automation and optimization of coal grinding by means of ball mills, Annals of DAAAM for 2011 \& Proceedings of the 22nd International DAAAM Symposium, ISBN 978-3-901509-83-4, ISSN 1726-9679, pp. 421-422, Editor B. Katalinic, Published by DAAAM International, Vienna, Austria 2011 